Article

\title{
The Total-Factor Energy Efficiency of Regions in China: Based on Three-Stage SBM Model
}

\author{
Haifeng Huang ${ }^{1}$ and Tao Wang ${ }^{2, *}$ \\ 1 HSBC Business School, Peking University, Shenzhen 518055, China; huanghf@phbs.pku.edu.cn \\ 2 Big Commodity Business School, Ningbo University of Finance and Economics, Ningbo 310300, China \\ * Correspondence: wtao93@vt.edu
}

Received: 14 August 2017; Accepted: 18 September 2017; Published: 19 September 2017

\begin{abstract}
This paper constructs a three-stage Slacks-Based Measure (SBM) model to evaluate and analyze the total-factor energy efficiency (TFEE) of 276 cities in China during the period of 2000-2012 from the management and environment dual perspectives according to the principles of multi-stage Data Envelopment Analysis (DEA) model. In the first stage, a SBM-DEA model is applied to assess TFEE scores to illustrate the effects of the energy factors, while considering the undesirable output. In the second stage, we adjust the original data, and then in the third stage, we use SBM model again to get efficiency evaluation and obtain pure management efficiency of every decision unit. The results show that Chinese TFEE is still low and energy saving potential can be up to $34-46 \%$, showing an inverted " $U$ " shape tendency and characteristic of regional imbalance. Based on these findings, we further put forward some paths and strategies to improve Chinese energy efficiency.
\end{abstract}

Keywords: three-stage SBM model; energy; spatial spillover; imbalance; efficiency

\section{Introduction}

Energy is always the important component for economic growth and social development, which provides not only an important source of power for life and production, but also important industrial raw materials. As a result of considerable increase in energy prices and concerns about sustainable development, the issue of energy efficiency gained much of the attention, public as well as scientific, during the last two decades. An important focus of these studies is how to improve energy efficiency without harming economic growth, which is the main problem that China is facing. China is in the rapid development period of urbanization and industrialization; with 15.5\% of global GDP in 2015, China has turned into the largest manufacturing power in the world. Meanwhile, China's industry has basically completed mid-stage industrialization and has entered its late stage. However, accompanied with the high-speed development of manufacturing, China has paid enormous costs for energy over-consumption (Figures 1 and 2) and serious environmental pollution. China's soaring demand for energy results from several factors that are central to the structure of the Chinese economy, and thus are quite clear. China is reliant on the fast expansion of the secondary industry, and particularly heavy industry. In addition, in recent years, China has increased its exports of energy-intensive products such as automobiles, machinery, and steel. The relocation of energy-intensive industries from the coastal region to the inland areas reduces the overall energy efficiency of the Chinese economy as well. All these factors result in high energy demand and low energy efficiency in the Chinese economy. In this context, the Chinese Government decisively put forward a legally binding energy efficiency target of decreasing energy intensity by $20 \%$ during the 12th five year plan time [1] and allocated the target to the provincial level. By adopting a comprehensive approach involving legal, administrative and economic means, the energy efficiency initiative has achieved remarkable results including a 19.1\% drop in energy intensity [1]. However, due to the lack of sufficient theoretical support and experience, 
most provinces have carried out their work blindly, promoted energy efficiency ineffectively, and faced unique difficulties not addressed by the "one-size-fits-all" national policy (Lu et al., 2015 [1]). In accordance with the investigation of the World Bank (2015) [2], China's energy cost is still between $8 \%$ and $12 \%$ of GDP. The total energy consumption has grown at a high rate, making China the second-largest energy consumer and largest $\mathrm{CO}_{2}$ emitter in the world. These imply the rigidity growth of energy consumption and serious environment pollution are dual constraints of Chinese economy growth. The effective way to break the constraints is to find paths to improve Chinese energy efficiency while the goal of research is to identify the main areas needing to improve energy efficiency. However, how to evaluate regional energy efficiency has become a primary problem. Since the first oil crisis (1973/1974) there has been a growing body of research in the field of energy studies (Tonini, 2016 [3]) and the issue of energy efficiency has become crucial component of energy strategy in many countries and regions for the last two decades. Assessing energy efficiency in macro-level policy analysis is usually done by two indicators: energy intensity (Bosseboeuf, Chateau and Lapillonne, 2000 [4]) and energy efficiency (Barcelona, 2007 [5]). While these traditional energy efficiency indexes take only energy into account as a singe input to produce output (GDP) while other inputs such as labor and capital are ignored, a new approach known as total-factor energy efficiency (TFEE) has been developed by Hu and Wang (2006) [6] to overcome the disadvantages of the traditional partial-factor energy efficiency and since then a number of papers have been published. (Some researchers (Honma and $\mathrm{Hu}, 2009$ [7]) concluded that the partial-factor energy efficiency estimation is misleading and cannot give the appropriate benchmark. This TFEE index provides a useful alternative to the traditional energy efficiency indicators mentioned above. It combines all three production factors as inputs and measures single-factor efficiency in a total-factor environment.) For example, Hu and Kao (2007) [8] calculate the energy saving ratio and energy savings per capita of 17 countries from Asia-Pacific Economic Cooperation (APEC) between 1991 and 2000 with TFEE. Honma and Hu (2009) [7] obtain the regional TFEE of Japan with the DEA model based on a dataset of 47 prefectures during the period 1993-2003. Moreover, some scholars consider undesirable outputs such as $\mathrm{SO}_{2}$ and $\mathrm{CO}_{2}$ to evaluate the environmental efficiency. For example, based on a non-radial DEA framework, Zhou et al. (2007) [9] evaluate the energy and environmental efficiency of 26 OECD countries from 1995 to 1997. The factors of labor, primary energy consumption, GDP, $\mathrm{CO}_{2}, \mathrm{SO}_{2}, \mathrm{NOx}$ and $\mathrm{CO}$ were all included as input or output factors in their study. Zhou et al. (2008) [10] develop several DEA-based environmental efficiency evaluation models for the measurement of the carbon emission efficiency of several world regions. Bian and Yang (2010) [11] proposed several DEA models to simultaneously measure resource (energy) and environmental efficiency and applied their models in the resource and environmental efficiency evaluation problem of 30 Chinese provinces. These prior studies enhance our knowledge, but they mainly focused on regional or sectional total energy efficiency, using gross domestic product as yield, with a few studies focusing on energy efficiency analysis of Chinese cities. These studies include those of $\mathrm{Li}$ and $\mathrm{Hu}$ (2012) [12], who estimated the TFEE of Chinese 210 cities from 1995 to 2006; Sun and Xiao (2012) [13], who studied the TFEE of Chinese Yangtze River Delta region from 1992 to 2010; Qin (2014) [14], who analyzed the TFEE of Chinese 230 element cities at the beginning of 2000s; and Lin and Du (2015) [15], who estimated the affection of market-oriented reforms on Chinese energy and $\mathrm{CO}_{2}$ emissions performance. However, none of the above studies meet the requirements of Chinese energy reduction, and are also biased estimations (Fukuyama et al., 2009 [16]), because they do not include non-consensual out-production of environment pollution (Bian et al., 2016 [17]). Some scholars use SBM (Slacks-Based Measure) model to make up for these shortcomings: Zhou et al. (2013) [18] proposed a non-radial DEA approach by integrating the entropy weight and SBM to access the environmental efficiency of the Chinese power industry at the provincial levels from 2005 to 2010; and Zhang and Choi (2013) [19] improved two SBM efficacy guides for modeling China's local energy and ecological activity during the 2001-2010. However, as SBM model only attributes factors affecting the energy efficiency of cities to input factors, and does not eliminate external environment factors, internal management factors and random error factors, its results are also biased and unfair 
(Timmer, 1997 [20]). Although multi-stage DEA model separates environment factors and management factors, other issues still exist that make method biased and unfair, for example ignoring environment constraints. The other problem is that the second stage of multi-stage DEA model is based on the space independence among evaluation units, but Pan (2012) [21] has shown Chinese TFEE has spatial correlation. Lesage and Pace (2010) [22] argued that ignoring spatial correlation will result in the omission of variables and increment of the total amount of biased factors, which may make estimation biased. In other words, even though all of the above evaluation methods account for the environment factors, it is difficult to ensure an accurate and fair assessment because of ignoring spillover impact of space among regions (a comprehensive review of the DEA approach in energy efficiency has been written by Mardani et al. (2016) [23]).

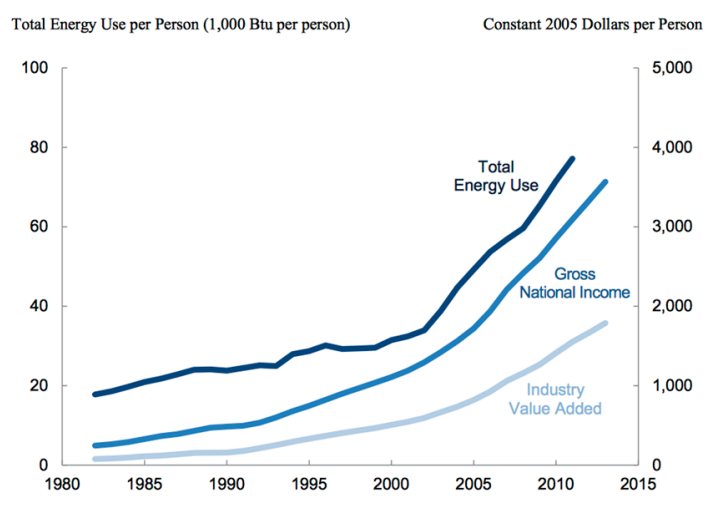

Figure 1. Per Capita Total Energy Use and Gross National Income in China, 1982-2013. Note: Data are from the Department of Energy, Energy Information Administration (www.eia.gov), and the World Bank. China became the world's largest user of energy in 2010 and is expected to remain in that position for the foreseeable future. As seeing from Figure 1, energy use in China has grown along with rising incomes and increasing industrial output in China. As a result of rising Chinese incomes, Chinese people generally consume more energy. Similarly, increases in the value added-the difference between the value of inputs and the value of outputs-by Chinese firms also contributed to increases in energy usage in China.

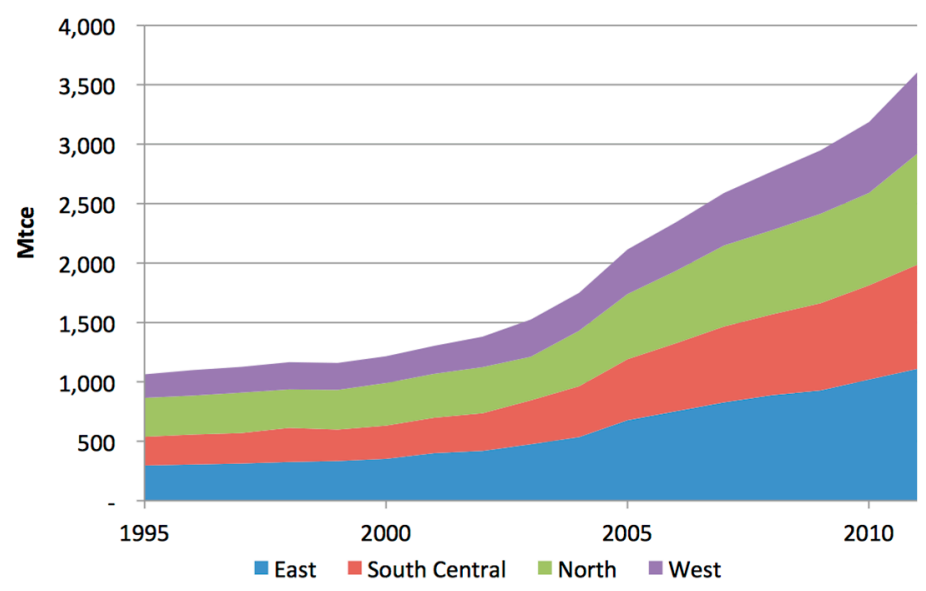

Figure 2. China's Total Energy Consumption by Region, 1995-2012. Note: Data are from the Department of Energy, Energy Information Administration (www.eia.gov), and the World Bank. As can be seen in Figure 2, the energy use in China has grown rapidly these years. Due to strong economic growth, China's energy consumption growth increased as a result of the country's industrial growth and quick development in major urban areas, particularly in the highly urbanized eastern region and the Pearl River Basin area in the south-central region. The east of China uses almost $1 / 3$ of all energy, while the west uses much less. 
In addition, a effective evaluation method not only needs to accurately, comprehensively and fairly assess the energy efficiency of the regions involved, but also needs to be able to find the reasons of invalid energy consumption. This effectiveness depends on the choice of evaluation indicators and units. Economists, engineers and environmentalists may have different definitions for energy efficiency and they choose various indicators to measure energy efficiency. At the macroeconomic stage, eco-efficiency was identified through indicators such as the relation between GDP and $\mathrm{CO}_{2}$ emissions. At the microeconomic level, eco-efficiency assessment has been extensively deliberated through total or relative singular events regarding the ecological activity indicators (Mardani et al., 2016 [23]). Hu and Wang (2006) [6] argue that unit GDP energy consumption evaluation method does not consider economy structure, technology level and other factors; it evaluates energy efficiency from a kind of single factor perspective and partial visual factor perspective. Therefore, based on multi-inputs and multi-outputs perspectives, the non-parametric DEA method is widely used to evaluate energy efficiency (Zhang, X. et al., 2011 [24]). Since the regional energy efficiency not only depends on the controlled variables, such as investment, but also exogenous environment effect, DEA model does not reveal the root reasons of energy inefficiency. (For evaluation indicators, Horta, Camanho and Dacosta (2009) [25] integrate the DEA approach and key performance indicators for evaluating efficiency.) The energy efficiency varies in different fields based on how to define the "energy input" and "useful output", thus sets of indicators are counted to serve a certain purpose. Previous arguments show that the choice of different indicators will have significant impact on the results (Goldemberg and Prado, 2011 [26]). For evaluation units, if we choose province, by different types of evaluation methods, Chinese energy efficiency of different regions will be completely different. The evaluation results based on the province unit can easily weaken the reliability of the conclusions. In other words, the choice of appropriate indicators and evaluation units to ensure accurate and fair assessments is the foundation for government to formulate "energy saving" policy, which is a problem worthy of further exploration. Recently, China has made some strategies to develop economy based on city agglomeration and cross-region countries economy zones. In the background of these strategies, it has been more difficult to meet the needs of Chinese energy problems based on the analysis of province unit. The city is China's relatively intact basic spatial unit and important area of economy development. In addition, the city is the most important sources of energy consumption and greenhouse gas emissions (Glaeser and Kahn, 2010 [27]), as the World Bank estimates 70\% of Chinese greenhouse gas emissions are generated by cities. The International Energy Agency predicts, by 2030, Chinese cities will account for $83 \%$ of the whole country's energy consumption [2]. Thus, energy evaluation based on the city unit can not only accurately reflect Chinese production space activities' patterns, but also benefit city managers as conducive to energy and environment policies, such as waste and traffic control (Hallegatte et al., $2011[28])$.

Therefore, the aim of this paper is to construct a three-stage SBM model (Chen et al., 2015 [29]; Nezinsky, 2015 [30]; Fukuyama et al., 2010 [31]) to evaluate and analyze the TFEE of 276 cities in China during the period of 2000-2012 from the management and environment dual perspectives according to the principles of multi-stage DEA model. Based on the evaluation framework of TFEE, we improve multi-stage SBM model by space econometrics method. We evaluate the TFEE of Chinese cities and find "Heights pool" and "Depression pool" areas. The empirical results indicate that, using province as evaluation unit, the multi-stage DEA model will ignore spatial spillover effect and overestimate the TFEE, thus its result would be biased and unfair. Management inefficiency and environment inefficiency are the reasons for Chinese energy inefficiency. Spatial cluster, industry structure, technology level, infrastructure and energy endowment are the key factors affecting Chinese TFEE and also the key directions for the regions with disadvantaged environment to improve their energy efficiency. The eastern region of China should focus on improving the quality of exogenous environment and energy efficiency while the mid-western and northeastern regions of China should focus on the strategies to improve their energy management capability. We further explore some methods to overcome Chinese energy inefficiency. This paper provides new empirical evidence on 
trends in energy efficiency of China and, consequently, it contributes to the existing energy efficiency literature by presenting an assessment of energy efficiency applying the three-stage SBM methodology.

The layout of the paper is as follows. Section 2 describes the methodology of models. Section 3 introduces data and variables, and obtains empirical results. Section 4 concludes paper.

\section{Methodology of Models}

In DEA models, we evaluate $n$ decision making units (DMUs), where each DMU takes $m$ different inputs to produce s different outputs. Inputs are organized in matrix $X$, element $x_{i j}$ meaning amount of input $i$ used by DMU $j$, and similarly in output matrix $Y$ [29].

$$
\mathbf{X}=\left[\begin{array}{cccc}
x_{11} & x_{12} & \ldots & x_{1 n} \\
x_{21} & x_{22} & \ldots & x_{2 n} \\
\vdots & \vdots & \ddots & \vdots \\
x_{m 1} & x_{m 2} & \ldots & x_{m n}
\end{array}\right] \quad \mathrm{Y}=\left[\begin{array}{cccc}
y_{11} & y_{12} & \ldots & y_{1 n} \\
y_{21} & y_{22} & \ldots & y_{2 n} \\
\vdots & \vdots & \ddots & \vdots \\
y_{s 1} & y_{s 2} & \ldots & y_{s n}
\end{array}\right]
$$

Given matrices $X$ and $Y$, for every $\mathrm{DMU}_{0}$, the following expressions hold:

$$
x_{0} \geq X \lambda, y_{0} \leq Y \lambda, \lambda \geq 0
$$

Production possibility set is thus described by above inequation, its frontier being points that are linear combinations of the efficient DMUs and present an "envelope" of the data. Indexes of variables $\lambda_{j}>0$ constitute the reference set $R_{0}$ (efficiency frontier), every frontier point being a positive linear combination of the other elements of the reference set:

$$
\hat{x}_{0}=\sum_{j \in R_{0}} x_{j} \lambda_{j}, \hat{y}_{0}=\sum_{j \in R_{0}} y_{j} \lambda_{j}
$$

By way of contrast to parametric production function approach, in DEA, no specific form of transformation function is assumed. Instead, the empirical frontier of production possibility set is constructed by linear combinations of the data of DMU under consideration. Thus, some DMUs can appear inefficient as one observes that the actual performance (activity) of one DMU is outperformed by a composite unit formed as a linear combination of some other DMUs. Figure 3 illustrates the efficiency measurement: each point in Figure 3 represents a combination of inputs that all produce the same level of output. Regions $C$ and D are on the frontier and they cannot maintain the given output level by further reducing their inputs. Regions A and B are therefore inefficient regions [29].

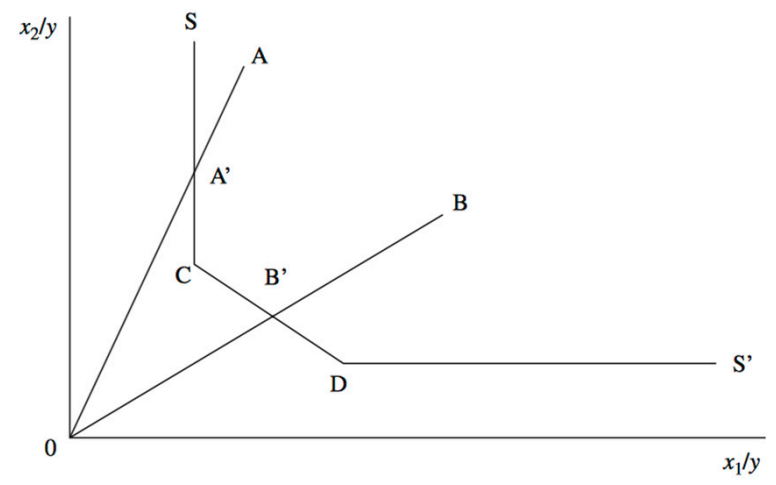

Figure 3. The DEA Efficiency Measurement. Note: In Figure 3, point $A^{\prime}$ is the best practice for region A by reducing the radial adjustment $\mathrm{AA}^{\prime}$. Point $\mathrm{A}^{\prime}$ can reduce some input to maintain the same output level. The reduced amount is called "input slack" (by the amount CA'). For region A, the best practice is point $C$, instead of point $A^{\prime}$, by reducing the radial adjustment $A^{\prime}$ and slack $C A^{\prime}$. 
However, as argued before, although multi-stage DEA model separates environment factors and management factors, other issues still exist that make the method biased and unfair. Specifically, the second stage of multi-stage DEA model is based on the space independence among evaluation units, but Pan (2012) [21] has shown Chinese TFEE has spatial correlation. Even when taking into account the environment factors, it is difficult to ensure an accurate and fair assessment because spillover impact of space among regions is ignored. For SBM model, it only attributes factors affecting the energy efficiency of cities to input factors, and does not eliminate external environment factors, internal management factors and random error factors. To solve these problems, Tone (2001) [32] has further developed the SBM Model to overcome the "Slack Issue" of the DEA Model in terms of DMU input factors, which has been widely accepted in this research. Li and $\mathrm{Hu}$ (2012) [12] also adopt the DEA-SBM method to calculate the TFEE of pollutants to exclude the effects from environmental factors and stochastic errors. As demonstrated by Tone and Tsutsui (2009) [33], traditional DEA models deal with measurements of relative efficiency of DMUs regarding multiple-inputs vs. multiple-outputs; one of the drawbacks of these models is the neglect of intermediate products or linking activities. They propose and demonstrate a slacks-based DEA model that can deal with intermediate products. Using this model, we can evaluate divisional efficiencies along with the overall efficiency of DMUs. Ashrafi et al. (2011) [34] argue that, unlike the radial two-stage DEA models, models based on the slacks-based measure (SBM) framework could enable us to determine efficient projections for inefficient DMUs. Thus, in this context, the objective of this paper is to combine these two models and use a three-stage SBM model (Nezinsky, 2015 [30]; Fukuyama et al., 2010 [31]) to evaluate the energy efficiency of Chinese cities based on the three-stage DEA model, which is composed of two traditional BCC (Banker, Charnes, Cooper) models and one SFA (Stochastic Frontier Approach) model. The main principles of model are as follows: The first stage is traditional BCC model, which is proposed by Banker, Charnes and Cooper (1984) [35], is the relative efficiency appraisal model based on multi-group input and output data. The second stage is the SFA model. To eliminate the influences of the external environmental factors and random errors on efficiency values, the SFA model is utilized to analyze the input margin. Then, in the third stage, we obtain the adjusted model. Figure 4 shows the framework of this model, and the detailed explanations follow.

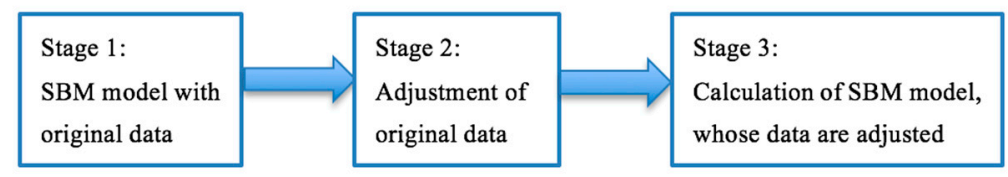

Figure 4. The Framework of Three-Stage SBM Model.

\subsection{Three-Stage SBM Model}

The most comprehensive measure of efficiency requires introducing input and output slack variables. In DEA, slacks act as exact measure of deviation from the frontier, which stands to describe best practice available given the technology. The meaning of slacks in DEA differs from that in managerial science where it could be less exact and have more qualitative substance. Inequality (1) can be then rewritten as [33]:

$$
\begin{aligned}
& x_{0}=X \lambda+s^{-} \\
& y_{0}=Y \lambda-s^{+}
\end{aligned}
$$

Output and input slack variables can be seen as a potential for underperforming units which can be reached by increasing output by $s^{+}$and reducing inputs by $s^{-}$. To eliminate the effect of exogenous environment and stochastic factors on the pure efficiency evaluation of the decision-making body, we build three-stage SBM model based on the three-stage DEA model. The principles and steps are as follows: 
(1) The first stage: SBM model with original data

Different from the traditional DEA model, SBM model can handle non-consensual output and takes into account the impact of slack variables. Thus, in this study, based on Tone's method (2001) [32], we use the input variables guide return SBM Model (SBM-I-V) to evaluate the TFEE of cities, as we can easily control decision-making unit by input element variables, and the non-consensual pollution output is mainly caused by input variable-energy consumption. Evaluation of efficiency itself takes the form of a fractional program:

$$
\rho=\min \frac{1-\frac{1}{m} \sum_{i=1}^{m} \frac{s_{i}^{-}}{x_{i 0}}}{1+\frac{1}{s} \sum_{i=1}^{S} \frac{s_{r}^{+}}{y_{r 0}}}
$$

Subject to:

$$
\begin{gathered}
x_{0}=X \lambda+s^{-} \\
y_{0}=Y \lambda-s^{+} \\
s^{-} \geq 0, s^{+} \geq 0, \lambda \geq 0
\end{gathered}
$$

where $\rho$ is the index we define, which has the properties of being unit invariant and monotone. Furthermore, every inefficiency given by slacks is penalized such that $0<\rho \leq 1$. When there is waste in input factors or the actual output is moving away from the optimal desirable output level on the production possibility frontier, the production level will be lower, which means $\rho$ will be smaller. When $\rho=1$, it means the input-output level or ratio of this DMU has reached optimization and the highest production efficiency. Vector $s^{-} \in R^{m}$ expresses excesses in inputs while vector $s^{+} \in R^{s}$ corresponds to shortages in outputs. $s^{+}$and $s^{-}$are called slacks. $s$ denotes the number of elements in s+ and $m$ denotes the number of elements in $s^{-}$. The variables $s^{+}$and $s^{-}$measure the distance of inputs $X \lambda$ and outputs $Y \lambda$ of a virtual unit from those of the unit evaluated $\left(X_{q}\right)$. The numerator and the denominator of the objective function of Model (4) measures the average distance of inputs and outputs, respectively, from the efficiency threshold. The fractional program (Equation (4)) can be linearized and solved for slacks and $\lambda$. Optimal non-zero solutions for $\lambda$ define set of indexes of efficient DMUs with all slacks equal zero. Thus, the measure of efficiency for efficient units is unit.

To give the model input orientation to reflect preferences and feasibility of the policy, output slacks are omitted in the objective function of Equation (4). Return to scale can be incorporated in the model the way proposed by Banker et al. (1984) [35], which consists in the additional constraint $e^{T} \lambda=1$ (e being the unit vector) allowing for variable returns to scale (VRS). SBM input oriented model with VRS takes the form of:

$$
\rho=\min 1-\frac{1}{m} \sum_{i=1}^{m} \frac{s_{i}^{-}}{x_{i 0}}
$$

Subject to:

$$
\begin{gathered}
x_{0}=X \lambda+s^{-} \\
y_{0}=Y \lambda-s^{+} \\
e^{T} \lambda=1 \\
s^{-} \geq 0, s^{+} \geq 0, \lambda \geq 0
\end{gathered}
$$

After determining relevant input and output variables, this measure can be used to assess efficiency of DMUs.

(2) The second stage: adjustment of original data

In this study, based on Coelli and coworkers' method (2005) [36], we separately establish space panel data model among slack variable of capital investment, slack variable of labor investment, slack 
variable of energy inputs and environment interpretation variable, namely spatial auto-regressive panel data model (SAR, Equation (6)) and spatial error regression panel data model (SEM, Equation (7)):

$$
\begin{gathered}
S_{i t}=\rho W_{s_{i t}}+z_{i t} \beta+u_{i t}, u_{i t} \sim\left(0, \sigma^{2} I\right)(i=1,2, \ldots, m) \\
S_{i t}=z_{i t} \beta+u_{i t} \\
u_{i t}=\gamma W_{u_{i t}}+\varepsilon_{i t}, \varepsilon_{i t} \sim\left(0, \sigma^{2} I\right)(i=1,2, \ldots, m)
\end{gathered}
$$

where Sit is slack variable; zit represents external environment variable; $\beta$ is corresponding coefficient vector; $u$ it is random error term; $i$ represents $i$ th decision unit; and $t$ represents period $t$ of the first stage.

Therefore, based on the data of Sit and zit, by SAR model and SEM Model, we can get $\hat{\beta}$, which is the estimation vector of $\beta$ [33]:

$$
\begin{aligned}
& \hat{S}_{i t}=\hat{\rho} W_{s_{i t}}+z_{i t} \hat{\beta} \\
& \hat{S}_{i t}=z_{i t} \hat{\beta}+\gamma W_{u_{i t}}
\end{aligned}
$$

Furthermore, because we cannot determine by experience which model is more suitable, SLM or SEM, we can choose Formula (8) or Formula (9) according to the basic principles that Anselin and Rey recommendation. If LMLAG (LM Test for Lagged Dependent) is more significant than LMERR (LM Test for Error Dependence) in statistics and R-LMLAG (Robust-LMLAG) is significant but R-LMERR (Robust-LMERR) not, then we use spatial lag model; otherwise, we use spatial error model. We can get the adjusted value of every single decision $\hat{S}_{i t}$ according to Model 8 and Model 9 . Thus, based on the worst decision unit of outside environment, according to the following model, we can make external environment equal:

$$
x_{i t}^{a d j}=x_{i t}+\left[\max \left\{\hat{S}_{i t}\right\}-\hat{S}_{i t}\right]
$$

where $x_{i t}^{a d j}$ is the input after adjustment and $x_{i t}$ is the original investment.

(3) The third stage: calculation of SBM model, whose data are adjusted

Use adjusted data in the second stage to replace original data in the first stage. Then, we use SBM-I-V model again to get efficiency evaluation and obtain pure management efficiency of every decision unit.

\subsection{TFEE Evaluation and Deconstruction Model}

In this study, we make TFEE of the target zones as the ratio between the expect value of energy and the actual value of energy and divide it into two parts: Total-Factor Energy Management Efficiency (TFEME) and Total-Factor Energy Environment Efficiency (TFEEE), which are shown as follows:

TFEME $=$ Adjusted expect value of the energy/Adjusted actual value of energy

$$
\text { TFEME }=\text { TFEE } / \text { TFEEE }
$$

Based on the above definition, TFEE assumes a value between zero and unity. A higher TFEE implies a higher level of energy efficiency. When TFEEE is less than 1, it means DMU is in inferior environment and the main factor making TFEE low is environment; when TFEEE equals to 1, it means environment has no effect on the TFEE; when TFEEE is greater than 1, it means DMU is in disadvantaged environment and the main factor making TFEE low is management factor.

\section{Empirical Results}

\subsection{Variables}

In this paper, we divide Chinese provinces and autonomous regions into four regions: eastern (east coast), central, western and northeastern (Figure 5), and choose 276 Chinese cities to be analyzed 
for their energy efficiency. According to the literature review of energy efficiency measurement (Chen et al., 2015 [29]), TFEE is the most widely used methods. However, two key issues of total factor inputs need to be resolved: how to determine input factors and how to gather all the inputs with different attributes, which is the basis of establishing the reliable energy efficiency index system. Currently, the production function, with energy, labor and capital as factors, proposed by Rashe and Tatom (1977) [37] is accepted and applied for the assessment of energy efficiency by most scholars (Chen et al., 2015 [29]). As for China, many people in the city still work many hours for their family and themselves to survive. A large number of activities are completed by workers on-site, and most of the processes are manual or accomplished by simple tools: overall, the Chinese industry is a typical labor-intensive industry with a low technological level (Liu et al., 2014a [38]; 2014b [39]). Meanwhile, according to these working-activities, people could obtain a certain amount of income by producing products and providing relevant services within a certain period. Besides, a certain amount of energy is consumed in the production process in city. Therefore, labor, capital and energy are the most basic factors in the operation process of the city industry. Currently, most scholars (Chen et al., 2015 [29]) consider the economic index and the physical index to be energy-utilization outputs: the economic index measures the services provided by energy utilization with market prices, while the physical index measures the services provided by energy utilization with physical units. Based on the features of the city industry and its energy consumption, two output indexes (GDP and $\mathrm{SO}_{2}$ ) were selected as the economic output and non-consensual output indicators indicators of the construction industry. In general, exogenous environmental variables are the factors that influence the energy efficiency of city and are out of the control of objective samples. Based on the literature review of the influencing factors of energy efficiency (Chen et al., 2015 [29]), and combining the development features of city, five aspects of environment variables are considered: industry structure, technology level, infrastructure, government intervention and energy endowment.

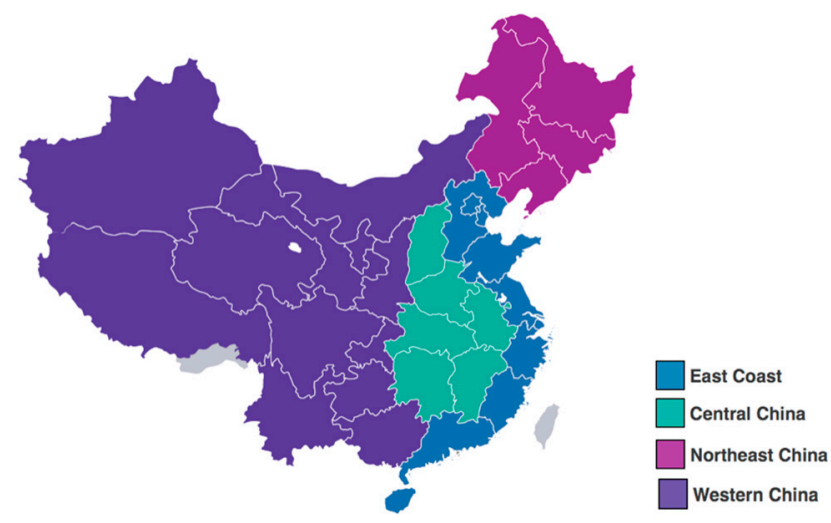

Figure 5. The Four Regions of Mainland China. Note: For geographical and political reasons, Mainland China is divided into four regions in 2011: eastern (east coast), central, northeastern and western. For decades, since Chinese economic reform in 1978, development priorities have been different among regions. As a result of the divide and policy preferences, the level of development differs much from each other, both economically and culturally. To help understand the divide, Mainland China map is drawn to identify the four regions and their provinces. East Coast, which is famous for its GDP contribution and economic development level, contains: Beijing, Tianjing, Shanghai, Hebei, Shandong, Jiangsu, Zhejiang, Fujian, Guangdong, Hong Kong, Macao, and Hainan. Central China, which is the base of agriculture, contains: Shanxi, Henan, Hubei, Anhui, Hunan, and Jiangxi. Northeast China, which is famous during 1950s-1990s, contains: Heilongjiang, Jining, and Liaoning. Western China, which has lowest population density and is least developed due to geographical reasons, contains: Inner Mongolia, Xinjiang, Ningxia, Shanxi, Gansu, Qinghai, Chongqing, Sichuan, Xizang, Guangxi, Guizhou, and Yunnan. 
Special description is as following:

1. Capital stock (K): Epitaxial expanding reproduction is the main growth mode of China's city. This is mainly because capital input is a driving force for the economic growth of city. At present, most scholars selected capital stock as an indicator for measuring capital input (Hu and Wang, 2006 [6]; Honma and $\mathrm{Hu}, 2008$ [7]). However, the methods to measure capital stock, for example the perpetual inventory method, may involve the utilization rate of capital or the depreciation rate of fixed assets, which are unavailable. Thus, we set physical capital stock as capital investment indicator and set fixed total investment as specific indicator. We estimate the capital stock of each city based on the "Perpetual Inventory law". Firstly, according to the following formula, the based capital stock of each city in 2001 is estimated.

$$
K_{2001}^{i}=I_{2001}^{i} /\left(g_{2001-2012}^{i}+\delta\right)
$$

where $K_{2001}^{i}$ represents the capital stock of city $i$ in 2001; $I_{2001}^{i}$ represents the fixed total investment of city $i$ in 2001; $g_{2001-2012}^{i}$ represents the average growth of the fixed total in-vestment of city $i$ from 2001 to 2012; and $\delta$. is the depreciation rate (6\%), which is proposed by Hall and Jones (1999) [40]. Then, we make the capital stock perpetual inventory.

2. Labor (L): As the city is a labor-intensive place, the development level and the competitiveness of city depend largely on the quality and quantity of labor. According to some research achievement, such as Hu and Wang (2006) [6] and Honma and $\mathrm{Hu}$ (2008) [7], we use the total number of the employed population in the current period as labor input indicator.

3. Energy investment (E): Because China has not comprehensively collected data of city energy consumption, we must get the data of energy investment another way. We choose annual electricity energy consumption as energy investment indicator, as electricity demand of GDP elasticity is very close to the total energy, and the power consumption data that computer readout are more accurate, electricity energy could more accurately represent the overall energy efficiency situation of China.

4. Economy output (Y): Currently, most scholars consider the economic index to be energy-utilization outputs, where the economic index measures the services provided by energy utilization with market price. Based on the features of city and its energy consumption, we use the real GDP of cities as economy output indicator.

5. Non-consensual output $\left(\mathrm{SO}_{2}\right)$ : For the same reason as above, the non-consensual indicator measures the services provided by energy utilization with physical units. We use sulfur dioxide emission of cities as a non-consensual output indicator.

6. Environment variables: At present, there are many studies on the factors impacting TFEE. Based on these studies (Chen et al., 2015 [29]; Liu et al., 2014a [38]; 2014b [39]), we choose five external environment factors. Industry structure: In cities with a developed industry, the market is relatively standard and effective competition could be fully realized, thereby stimulating each enterprise to improve their own productivity. Technology level: Cohen and Levinthal (1989) [41] propose that technology investment could strength the ability to absorb information, promote the transfer of knowledge and improve innovation. Advanced technology also promotes the development of renewable energy, such as solar power and wind power, which has higher efficiency and less environmental side effect. Therefore, technology level is the key factor in increasing energy efficiency. Infrastructure: The city with well-developed infrastructure could make resource allocation more reasonable and the agglomeration and scale effects stronger. Government intervention: As Chinese government is now trying its best to reduce waste and low-efficiency energy, if in a city, the government is putting reducing energy waste as its main job, then usually the energy efficiency of this city will be higher. Energy endowment: The energy endowment has a significant influence on energy efficiency. At present, energy endowment in most Chinese cities depends on raw coal, petroleum, diesel and electrical power. However, 
there are some differences in the energy level of different cities. Compared with coal, electrical power is high-efficiency energy [29]. Special indicators are: (1) output value of the second industry/regional total product (IN/GDP); (2) foreign direct investment/fixed total investment (FDI/I); (3) cargo volume/(highway mileage+railway mileage) (T/H); (4) expenditure/regional total product (CZ/GDP); and (5) the number of employees in mining industry/the total number of employees (CJ/TW).

The original data of all the above indicators are from "Chinese town and city statistics yearbook (2001-2012)" [42], "Chinese regional economic statistics yearbook (2001-2012)" [43] and "Chinese statistics yearbook (2001-2012)" [44] published by National Bureau of Statistics of China each year.

\subsection{First Stage: Evaluation of TFEE and District Differences}

From the national perspective, Chinese TFEE from 2001 to 2012 is between 0.54 and 0.66 and mean is 0.57 (Table 1), which indicates, under the premise of keeping output unchanged, we could save $34-46 \%$ of total energy consumption. These results are significantly lower than the evaluation efficiency based on the province unit. From 2001 to 2012, the TFEE rises from 0.54 in 2001 to 0.66 in 2010, and then decreases to 0.58 in 2012, which displays an inverted " $U$ " type (Figure 6). During the "Eleventh Five-Year" and "Twelfth Five-Year" period (referred to as "two-five period" below), as government shuts down some high energy consumption and pollution companies, the TFEE rises as a whole. Stagnation and decline after 2010 is mainly due to the distorted energy factor price and "Four Trillion Investment Plan", which result in extensive and rough economy development. At the same time, the standard deviation of TFEE also shows "U" type (Figure 7): from 0.25 in 2001, it declines to 0.18 in 2010 and then rises to 0.21 in 2012. The results show, during the whole study period, the TFEE tends to diverge as a whole, but, during "two-five period", it tends to converge.

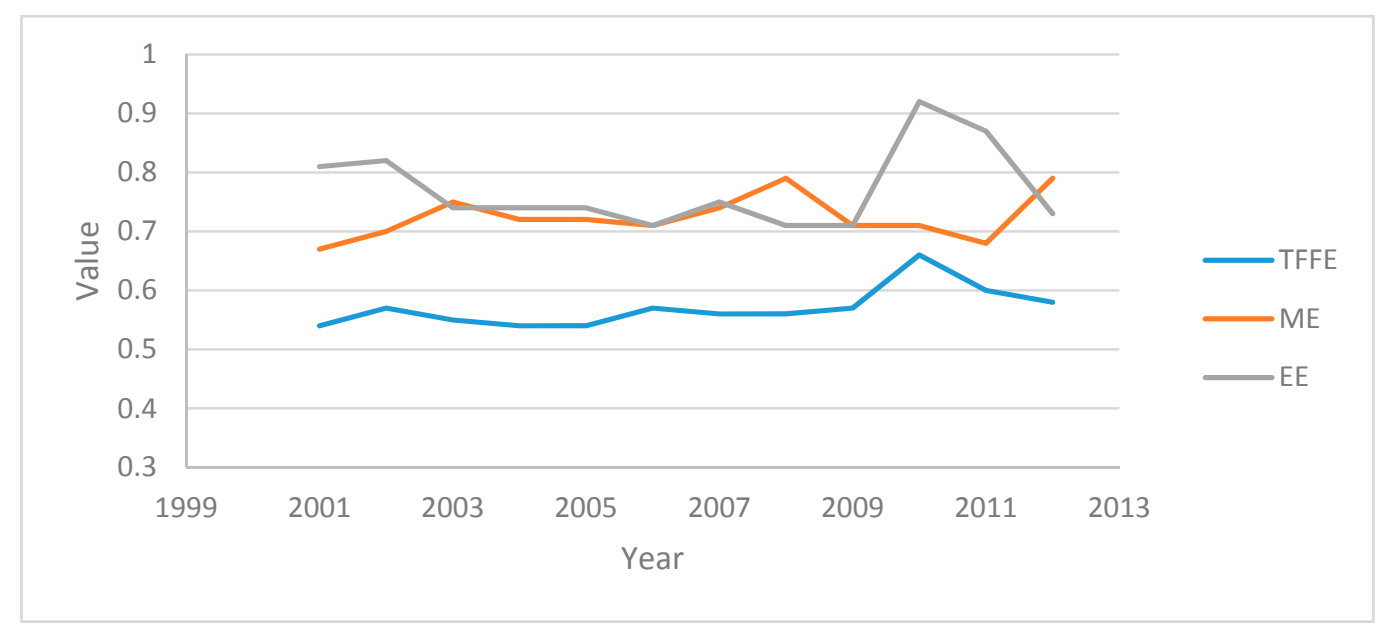

Figure 6. The Value of TFEE, ME and EE. Note: The TFEE rises from 0.54 in 2001 to 0.66 in 2010, and then decreases to 0.58 in 2012, which displays an inverted " $U$ " type.

From the major cities perspective, the following can be seen. First, the last 10 cities whose TFEE are lowest are mainly located in the central and western regions, which are all resource-based cities. Second, from 2001 to 2012, the total number of cities whose efficiency is in frontier are between 27 and 37 (Table 2), most of them are province capitals and economically developed cities located in Yangtze River Delta region and Pearl River Delta region. At the same time, the efficiency of some provincial cities of the mid-western and northeastern regions are also in frontier, such as Shenyang, Changchun, Chengdu, Chongqing and Changsha. From 2001 to 2012, the Full Global Moran Index value of TFEE of cities are all positive and pass the significance test (Table 3), which shows the TFEE of China is 
spatial cluster and cities who have higher spatial cluster of population and economy activities also have higher TFEE.

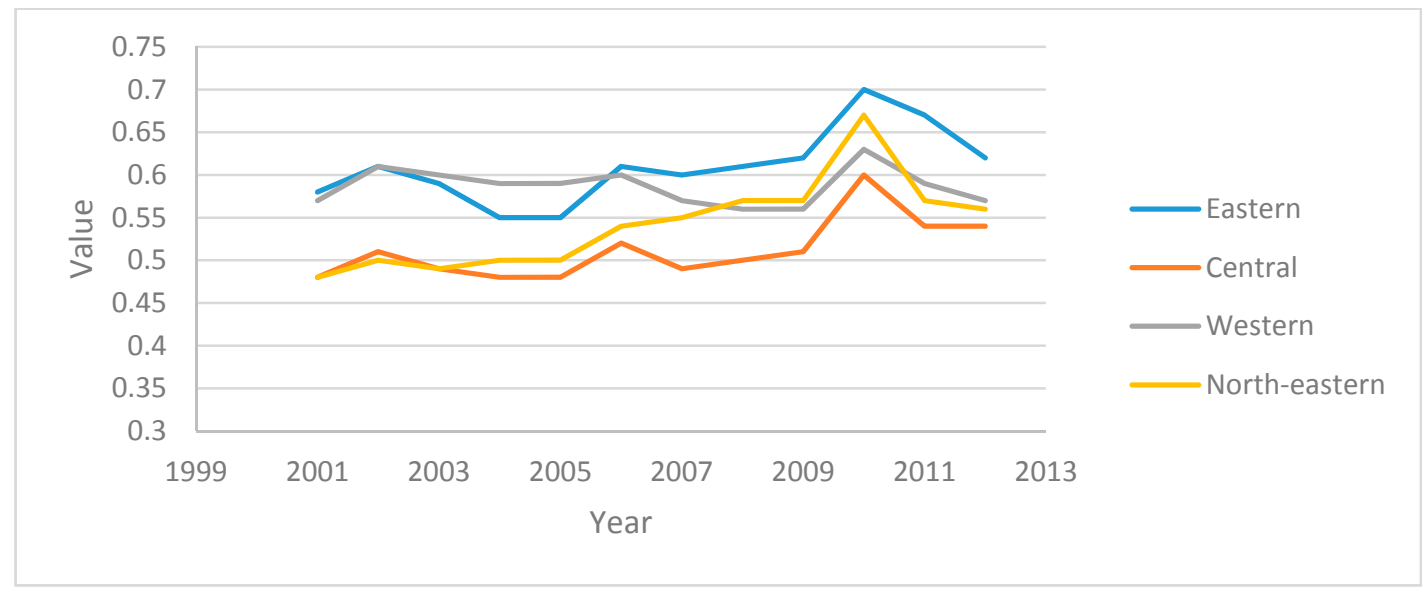

Figure 7. The Value of TFEE of Four Regions. Note: The TFEE declines from 0.25 in 2001 to 0.18 in 2010, and then rises to 0.21 in 2012, which displays a " $U$ " type.

Table 1. The Value of Chinese TFEE, ME and EE.

\begin{tabular}{ccccccccccccccccc}
\hline & \multicolumn{3}{c}{ National } & \multicolumn{3}{c}{ Eastern } & \multicolumn{4}{c}{ Central } & \multicolumn{3}{c}{ Western } & \multicolumn{3}{c}{ North-Eastern } \\
\cline { 2 - 7 } & TFFE & ME & EE & TFFE & ME & EE & TFFE & ME & EE & TFFE & ME & EE & TFFE & ME & EE \\
\hline 2001 & 0.54 & 0.67 & 0.81 & 0.58 & 0.66 & 0.88 & 0.48 & 0.64 & 0.75 & 0.57 & 0.69 & 0.82 & 0.48 & 0.66 & 0.72 \\
2002 & 0.57 & 0.70 & 0.82 & 0.61 & 0.71 & 0.86 & 0.51 & 0.66 & 0.78 & 0.61 & 0.70 & 0.87 & 0.50 & 0.73 & 0.68 \\
2003 & 0.55 & 0.75 & 0.74 & 0.59 & 0.79 & 0.74 & 0.49 & 0.73 & 0.67 & 0.60 & 0.71 & 0.84 & 0.49 & 0.79 & 0.62 \\
2004 & 0.54 & 0.72 & 0.74 & 0.55 & 0.75 & 0.74 & 0.48 & 0.71 & 0.67 & 0.59 & 0.69 & 0.84 & 0.50 & 0.75 & 0.68 \\
2005 & 0.54 & 0.72 & 0.74 & 0.55 & 0.75 & 0.74 & 0.48 & 0.71 & 0.67 & 0.59 & 0.69 & 0.85 & 0.50 & 0.75 & 0.68 \\
2006 & 0.57 & 0.71 & 0.71 & 0.61 & 0.72 & 0.85 & 0.52 & 0.70 & 0.74 & 0.60 & 0.70 & 0.86 & 0.54 & 0.75 & 0.72 \\
2007 & 0.56 & 0.74 & 0.75 & 0.60 & 0.75 & 0.80 & 0.49 & 0.71 & 0.69 & 0.57 & 0.73 & 0.78 & 0.55 & 0.77 & 0.71 \\
2008 & 0.56 & 0.79 & 0.71 & 0.61 & 0.79 & 0.78 & 0.50 & 0.77 & 0.64 & 0.56 & 0.78 & 0.71 & 0.57 & 0.83 & 0.68 \\
2009 & 0.57 & 0.71 & 0.71 & 0.62 & 0.71 & 0.88 & 0.51 & 0.68 & 0.76 & 0.56 & 0.73 & 0.77 & 0.57 & 0.74 & 0.77 \\
2010 & 0.66 & 0.71 & 0.92 & 0.70 & 0.75 & 0.93 & 0.60 & 0.70 & 0.86 & 0.63 & 0.74 & 0.85 & 0.67 & 0.71 & 0.95 \\
2011 & 0.60 & 0.68 & 0.87 & 0.67 & 0.73 & 0.92 & 0.54 & 0.66 & 0.81 & 0.59 & 0.68 & 0.86 & 0.57 & 0.63 & 0.91 \\
2012 & 0.58 & 0.79 & 0.73 & 0.62 & 0.81 & 0.76 & 0.54 & 0.78 & 0.70 & 0.57 & 0.77 & 0.74 & 0.56 & 0.77 & 0.72 \\
mean & 0.57 & 0.72 & 0.77 & 0.61 & 0.74 & 0.82 & 0.51 & 0.70 & 0.73 & 0.59 & 0.72 & 0.82 & 0.54 & 0.74 & 0.74 \\
N & & 276 & & & 87 & & & 79 & & & 76 & & & 34 \\
\hline
\end{tabular}

Note: ME represents total-factor energy management efficiency, which we use as TFEME in the following sections; EE represents total-factor energy environment efficiency, which we use as TFEEE.

Table 2. The Top 10 and Bottom 10 TFEE of Chinese Cities.

\begin{tabular}{|c|c|c|c|c|}
\hline & 2001 & 2005 & 2010 & 2012 \\
\hline Top 10 & $\begin{array}{l}\text { Tianjin, Shenyang, } \\
\text { Changchun, Shanghai, } \\
\text { Wuxi, Hangzhou, } \\
\text { Guangzhou, Shenzhen, } \\
\text { Dongguan, Chengdu }\end{array}$ & $\begin{array}{l}\text { Changchun, Shanghai, } \\
\text { Wuxi, Suzhou, Hangzhou, } \\
\text { Guangzhou, Shenzhen, } \\
\text { Foshan, Chongqing, } \\
\text { Dongguan }\end{array}$ & $\begin{array}{l}\text { Beijing, Shenyang, } \\
\text { Shanghai, Suzhou, } \\
\text { Changsha, Guangzhou, } \\
\text { Shenzhen, Foshan, } \\
\text { Dongguan, Chongqing }\end{array}$ & $\begin{array}{c}\text { Beijing, Tianjing, Shanghai, } \\
\text { Suzhou, Qingdao, } \\
\text { Changsha, Guangzhou, } \\
\text { Shenzhen, Foshan, } \\
\text { Chongqing }\end{array}$ \\
\hline Bottom 10 & $\begin{array}{l}\text { Cangzhou, Yingkou, Fuxin, } \\
\text { Shizuishan, Yinchuan, } \\
\text { Tongchuan, Xingtai, } \\
\text { Xining, Puyang, Jiaozuo }\end{array}$ & $\begin{array}{c}\text { Fuxin, Changzhi, } \\
\text { Shangqiu, Tongchuan, } \\
\text { Yingkou, Hegang, Puyang, } \\
\text { Xining, Jiaozuo, Yinchuan }\end{array}$ & $\begin{array}{c}\text { Puyang, Anyang, } \\
\text { Xinxiang, Fuxin, Zhoukou, } \\
\text { Jiaozuo, Nanyang, } \\
\text { Guiyang, Yingkou, } \\
\text { Shangqiu }\end{array}$ & $\begin{array}{c}\text { Handan, Yingkou, } \\
\text { Guangyuan, Anyang, } \\
\text { Jiaxing, Puyang, Nanyang, } \\
\text { Guiyang, Jiaozuo, } \\
\text { Shangqiu }\end{array}$ \\
\hline Frontier Cities & 33 & 27 & 33 & 36 \\
\hline
\end{tabular}


Table 3. The Moran's I Value of Chinese TFEE From 2001 to 2012.

\begin{tabular}{ccccccccccccc}
\hline Year & $\mathbf{2 0 0 1}$ & $\mathbf{2 0 0 2}$ & $\mathbf{2 0 0 3}$ & $\mathbf{2 0 0 4}$ & $\mathbf{2 0 0 5}$ & $\mathbf{2 0 0 6}$ & $\mathbf{2 0 0 7}$ & $\mathbf{2 0 0 8}$ & $\mathbf{2 0 0 9}$ & $\mathbf{2 0 1 0}$ & $\mathbf{2 0 1 1}$ & $\mathbf{2 0 1 2}$ \\
\hline Moran's I & 0.112 & 0.148 & 0.14 & 0.104 & 0.086 & 0.101 & 0.089 & 0.081 & 0.088 & 0.177 & 0.135 & 0.114 \\
Z & 4.823 & 6.305 & 5.968 & 4.49 & 3.746 & 4.361 & 3.87 & 3.526 & 3.827 & 7.543 & 5.785 & 4.917 \\
\hline
\end{tabular}

\subsection{Second Stage: The Environment Impact of TFEE and Reasons of Differences}

As shown in Tables 3 and 4, the TFEE of Chinese cities have spatial cluster. Based on this, we build spatial lag model and spatial error model, whose explained variables are slack variables of the investment variables of the first stage's DMUs and dependent variables are industry structure, technology level, infrastructure, government intervention and energy endowment. We make reciprocal of distance among cities as space weight and estimate fixed effects spatial panel data model with the method of maximum likelihood estimation. The regression results are shown in Table 4, which show industry structure, technology level, infrastructure and energy endowment have significant impact on energy slack variables.

Table 4. The Regression Results of Second Stage of Spatial Econometric Model.

\begin{tabular}{ccccccc}
\hline \multirow{2}{*}{$\begin{array}{c}\text { Variable/ } \\
\text { Model }\end{array}$} & \multicolumn{2}{c}{ Capital Slack Variable } & \multicolumn{2}{c}{ Labor Slack Variable } & \multicolumn{2}{c}{ Energy Slack Variable } \\
\cline { 2 - 7 } & SAR & SEM & SAR & SEM & SAR & SEM \\
\hline \multirow{2}{*}{ IN/GDP } & -1.7 & -1.7 & -0.07 & -0.05 & 2.92 & 2.17 \\
& $(5.05)^{* * *}$ & $(5.03)^{* * *}$ & $(0.566)^{* * *}$ & $(0.42)$ & $(10.61)^{* * *}$ & $(5.46)^{* * *}$ \\
\hline \multirow{2}{*}{ FDI/I } & -0.01 & -0.01 & -0.01 & -0.01 & -0.01 & -0.01 \\
& $(3.04)^{* * *}$ & $(3.09)^{* * *}$ & $(0.32)$ & $(0.28)$ & $(2.52)^{*}$ & $(2.28)^{*}$ \\
\hline \multirow{2}{*}{ H/T } & 0.47 & $0.55^{* * *}$ & 0.02 & 0.09 & -0.27 & -0.46 \\
& $(5.15)^{* * *}$ & $(6.07)^{* * *}$ & $(0.65)$ & $(3.11)^{* * *}$ & $(3.72)^{* * *}$ & $(4.90)^{* * *}$ \\
\hline \multirow{2}{*}{$\mathrm{CZ} / \mathrm{GDP}$} & 0.33 & 0.65 & 0.44 & 0.55 & 0.66 & 0.37 \\
& $(0.56)$ & $(1.13)$ & $(2.94)^{* *}$ & $(3.57)^{* * *}$ & $(1.43)$ & $(0.73)$ \\
\hline \multirow{2}{*}{$\mathrm{CJ} / \mathrm{TW}$} & 1.13 & 1.13 & 0.22 & 0.13 & 0.78 & 1.09 \\
& $(3.37)^{* * *}$ & $(3.37)^{* * *}$ & $(1.31)$ & $(0.77)$ & $(2.83)^{* * *}$ & $(1.92)$ \\
\hline \multirow{2}{*}{$\lambda / \rho$} & 0.35 & 0.04 & 0.61 & 0.34 & 0.64 & 0.6 \\
\hline$R^{2}$ & $(3.10)^{* * *}$ & $(0.28)$ & $(8.37)^{* * *}$ & $(2.71)^{* *}$ & $(9.46)^{* * *}$ & $(7.77)^{* * *}$ \\
\hline $\log \mathrm{C}$ & 0.52 & 0.5 & 0.52 & 0.51 & 0.59 & 0.58 \\
\hline Model & -7355.14 & -7350.19 & -1277.15 & -1270.45 & -5112.59 & -5171.03 \\
\hline
\end{tabular}

Notes: “***", “***", and "**", respectively, represent significant level test of $1 \%, 5 \%$ and $10 \%$. The numbers in parentheses are $t$ values.

\section{(1) Industry structure}

The correlation between industry structure and energy slack variables are significantly positive, indicating the increment of the proportion of secondary industry investment is not benefit for saving power investment. Industry structure and capital slack variables are negatively correlated and pass the $1 \%$ significant test, indicating the increment of the proportion of secondary industry investment can help save capital investment. The estimated coefficient between industry structure and labor slack variables are negative and fail to pass the significant test, therefore we should eliminate it when adjusting labor input variables.

(2) Technology level

The correlation between technology level and energy slack variables as well as between technology level and capital slack variables are significantly negative, indicating the increment of the proportion 
of foreign direct investment (FDI) benefits saving power and capital investment and increasing TFEE. The estimated coefficient between technology level and labor slack variables are negative and fail to pass the significant test, therefore we should eliminate it when adjusting labor input variables.

\section{(3) Infrastructure}

The correlations between infrastructure and energy slack variables are significantly negative, indicating constantly improving the quality of transport infrastructure can promote the enhancement of TFEE. If the quality of transport infrastructure within a city and between citis continues to improve, it will help enhance the flow of production factors and production activities, which will also benefit element optimization and enhance the externalities of spatial agglomeration. Eventually, it will promote the TFEE. The correlation between infrastructure and capital slack variables, infrastructure and labor slack variables are significantly positive.

\section{(4) Government intervention}

The estimated coefficient between the expenditure ratio of GDP and energy slack variables, expenditure ratio of GDP and capital slack variables are positive, but fail to pass the significant test, therefore we should eliminate it when adjusting labor input variables. Considering that, when we use the expenditure ration of GDP to measure the level of government intervention in the economy, we find the estimated coefficient between expenditure ratio of GDP and energy slack variables are positive, the opposite effect occurs. The main reason is that, to promote local economy growth, the government will reduce the requirements for companies reducing emission and saving power. In other words, government tends to promote economy growth at the expense of environment quality. Due to the government intervention and the tendency of environment governance "Ride", it will be more difficult to predict the influence of industry agglomeration on energy efficiency. In SEM model, the estimated coefficients between government intervention and labor slack variables pass the significant test.

\section{(5) Energy endowment}

The estimated coefficient between the energy endowment and labor slack variables, energy endowment and capital slack variables are both positive and pass the significant test, which confirms the previous analysis that the TFEE of resource-based cities are often very low and become the "curse" between energy endowment and TFEE. The estimated coefficient between energy endowment and labor slack variables does not pass the significant test, so we should eliminate it when adjusting labor input variables.

\subsection{Third Stage: Structure Decomposition of TFEE and Promotion Paths}

According to the adjusted input variables in the second stage, we estimate energy efficiency again (Table 1). The results show the TFEE and TFEME are significantly different. Thus, excluding the evaluation deviation caused by external environment differences is essential.

From the national perspective, during the study period, Chinese TFEME is between 0.67 and 0.79 and the mean is 0.72 , which is significantly higher than the TFEE (up to $27.04 \%$, Table 1 ). At the same time, all the TFEEE is less than 1 and the average during the study period is 0.77 , which indicates management inefficiency and environment inefficiency are the main reasons Chinese TFEE is low. If we do not eliminate the external influence of inferior environment, we will underestimate Chinese TFEME. From 2001 to 2012, Chinese TFEME as a whole fluctuated and rose. Specifically, the TFEME increases slowly from 2001 to 2010 and then enters downward road; in 2012, it shows a strong rebound. The TFEEE shows the tendency of wandering forward from 2001 to 2007, becoming worse from 2008 to 2011, and greatly improving in 2012. This change trajectory is different from the TFEME, which indicates the current Chinese TFEE is mainly affected by the change in TFEEE. Improving exogenous environment is an important direction to enhance Chinese TFEE (Figure 6). 
From the regional perspective: (1) The TFEME of eastern region is higher than the national average from 2001 to 2012. It ranges from 0.66 to 0.81 and the mean is 0.74 (Table 1), which shows the steady risen tendency overall and from 2009 to 2010, after a slight decline, it rises rapidly. At the same time, the TFEME is significantly higher than the TFEE and the development tendency contrasts sharply with the latter. During the same period, all the TFEEE is less than 1, consistent with the national development tendency, which shows the reason that making the TFEE of eastern region low is the impact of the deterioration of the TFEEE. (2) The TFEME and tendency of central region are the same as the nation from 2001 to 2012. It ranges from 0.64 to 0.78 and mean is 0.72 (Table 1). All the TFEEE are less than 1 and lower than the national average. At the same time, the TFEME is significantly higher than the TFEE, which shows the reason that making the TFEE of central region low is the impact of the deterioration of environment. (3) The TFEME and development tendency of western region are the same as national average from 2001 to 2012. Before 2008, it is a little lower than national average, but, after 2008, it is a little higher than national average. All the TFEEE is less than 1, but significantly higher than national average, which shows western region has a higher TFEEE, but is still an important constraint to enhance the TFEE. (4) The TFEME of northeast region is a little higher than the national average from 2001 to 2012, but has the same development tendency with nation. During "two-five period", its TFEEE is below the national level, but, in recent years, it has caught up with the nation.

Regional comparison results show, overall, the eastern region has the highest TFEME while the western region is lowest. From 2001 to 2007, western region has the highest TFEEE, but then it is replaced by eastern region. The central and northeastern regions are always inefficient. This suggests, overall, eastern region has higher TFEME and TFEEE, and although central, western and northeastern regions take some action to enhance their TFEE, they should prevent exogenous environment deteriorated when enhancing the level of energy management (Figures 8 and 9).

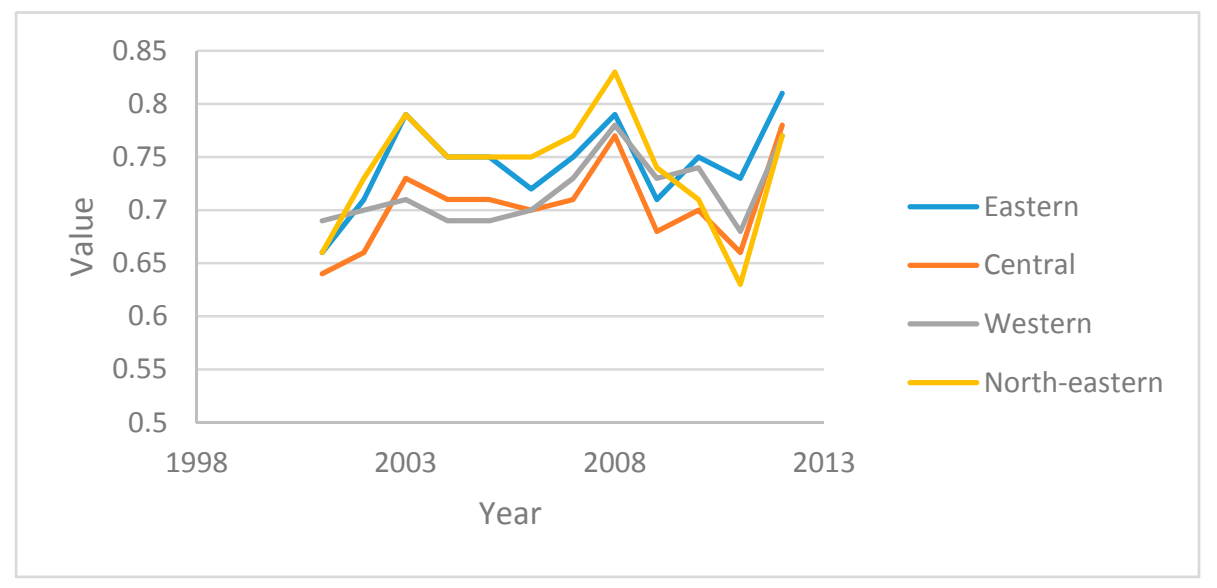

Figure 8. The Value of ME of Four Regions. Note: Overall, the eastern region has the highest TFEME while the western region is lowest.

From the major cities perspective, the Bottom 10 cities, whose TFEME are lowest, are mainly located in the central and western regions (Table 5). The efficiency of Beijing, Tianjin, Shanghai, Guangzhou, Chongqing, Changsha and Shenyang are always in frontier. After excluding external environment factor in 2010, some cities exit from frontier, including Chengdu, Dongguan, Hangzhou, Tianjin, Tangshan, Jieyang and Zibo, which indicates the TFEE of these cities benefit from better external environment. Some cities enter frontier, including Baoji, Baoding, Changde, Chuzhou, Dalian, Haikou, Meizhou, Qingdao, etc., which shows some cities of the central region and western region also have higher TFEME. 


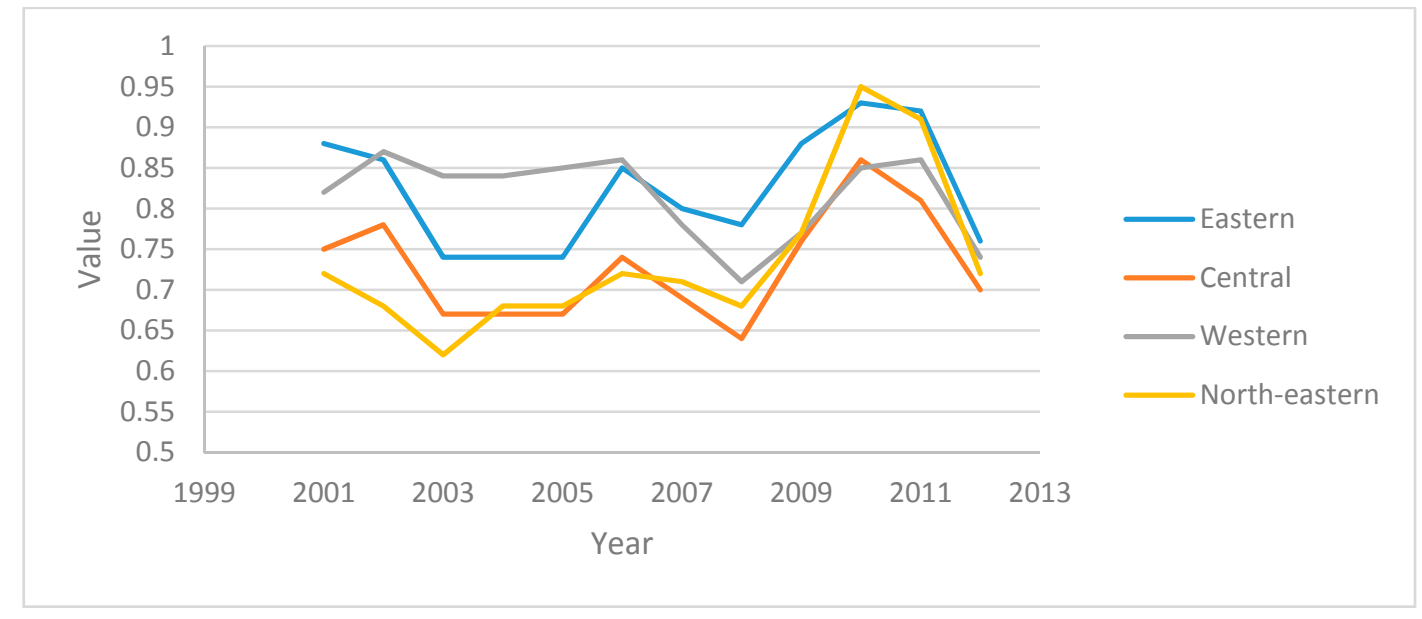

Figure 9. The Value of EE of Four Regions. Note: From 2001 to 2007, western region has the highest TFEEE, but then it is replaced by eastern region.

Table 5. The Top 10 and Bottom 10 TFEME of Chinese Cities.

\begin{tabular}{|c|c|c|c|c|}
\hline & 2001 & 2005 & 2010 & 2012 \\
\hline Top 10 & $\begin{array}{l}\text { Tianjin, Shenyang, } \\
\text { Changchun, Shanghai, } \\
\text { Wuxi, Hangzhou, } \\
\text { Guangzhou, Shenzhen, } \\
\text { Dongguan, Chengdu }\end{array}$ & $\begin{array}{l}\text { Changchun, Shanghai, } \\
\text { Wuxi, Suzhou, } \\
\text { Hangzhou, Guangzhou, } \\
\text { Shenzhen, Foshan, } \\
\text { Chongqing, Dongguan }\end{array}$ & $\begin{array}{l}\text { Beijing, Shenyang, } \\
\text { Shanghai, Suzhou, } \\
\text { Changsha, Guangzhou, } \\
\text { Shenzhen, Foshan, } \\
\text { Dongguan, Chongqing }\end{array}$ & $\begin{array}{l}\text { Beijing, Tianjing, } \\
\text { Shanghai, Suzhou, } \\
\text { Qingdao, Changsha, } \\
\text { Guangzhou, Shenzhen, } \\
\text { Foshan, Chongqing }\end{array}$ \\
\hline Bottom 10 & $\begin{array}{l}\text { Cangzhou, Yingkou, } \\
\text { Fuxin, Shizuishan, } \\
\text { Yinchuan, Tongchuan, } \\
\text { Xingtai, Xining, Puyang, } \\
\text { Jiaozuo }\end{array}$ & $\begin{array}{c}\text { Fuxin, Changzhi, } \\
\text { Shangqiu, Tongchuan, } \\
\text { Yingkou, Hegang, } \\
\text { Puyang, Xining, Jiaozuo, } \\
\text { Yinchuan }\end{array}$ & $\begin{array}{l}\text { Puyang, Anyang, } \\
\text { Xinxiang, Fuxin, } \\
\text { Zhoukou, Jiaozuo, } \\
\text { Nanyang, Guiyang, } \\
\text { Yingkou, Shangqiu }\end{array}$ & $\begin{array}{l}\text { Handan, Yingkou, } \\
\text { Guangyuan, Anyang, } \\
\text { Jiaxing, Puyang, } \\
\text { Nanyang, Guiyang, } \\
\text { Jiaozuo, Shangqiu }\end{array}$ \\
\hline Frontier Cities & 33 & 27 & 33 & 36 \\
\hline
\end{tabular}

Based on the differences of TFEME and TFEEE among cities, we put forward some strategies that can improve the TFEE: (1) Cities whose mean of TFEME is less than 1 and mean of TFEEE is greater than 1 from 2001 to 2012 should improve their energy management capabilities. These cities include: Beijing, Zhangjiajie, Lijiang, Yingtan, Xuancheng, Ningde, Guyuan, Bozhou, Erdos, Dongguan, Qingyang, Qinzhou, Fuzhou, Zhongshan, Meishan, Fangchenggang, Beihai, Jieyang, Baise, Pakistan, JadeCreek, Jiayuguan, Wuzhong, Heihe, Shangluo, Suizhou, Dongying, Qujing, PoolStates, Lishui, Pingliang, Changde, Sanya, Suihua, Daqing, Hezhou, Wuxi, Guiyang, Chongzuo, Chengdu, Huzhou, Changsha, Guang'an and Changzhou. (2) Cities whose mean of TFEME equal to 1 and mean of TFEEE is less than 1 from 2001 to 2012 should improve their exogenous environment. These cities include Shanghai, Guangzhou, Shenzhen, Chongqing, Foshan, Shenyang and Suzhou. (3) The remaining cities should improve energy management capability and exogenous environment at the same time to improve their TFEE.

\section{Conclusions}

Improving energy efficiency is the main direction to achieve the goal of emission reduction. The problems of accurate assessment of Chinese energy efficiency and its regional differences and identifying the reasons of energy inefficiency have caught researchers' widespread concerns. Accurate evaluation of energy efficiency requires appropriate evaluation methods and assessment units. The existence indicators of per unit production energy consumption and TFEE have fully taken into account the comprehensive factors of evaluation units and achieved transition from single view to integrated view, but they fail to exclude spatial spillover effect among cities and effect of environment and 
random factors. These evaluation methods are biased and unfair for regions that have disadvantaged environment and cannot identify the reasons for their energy inefficiency. Because China has large regional differences, if we choose province as evaluation unit, different evaluation methods will get different results. Since the city is relatively complete base space unit and the most important source of energy consumption, we construct three-stage spatial econometrics SBM model based on the principles of multi-stage DEA model. From the perspective of management and environment, we evaluate and deconstruct TFEE of 276 Chinese cities from 2001 to 2012. We identify exogenous environment and then put forward some strategies to enhance energy efficiency. Comparing with other authors' results, we find similar conclusions, but most of them consider from province unit. Zhang et al. (2013) [19] analyzed the energy efficiency in China with eight economics zones and it indicated that the energy decreased gradually from southeast to northwest between 1998 and 2005. Hu and Wang (2006) [6] found regions in the east area have the highest rank of total factor energy efficiency, while regions in the central area have the worst efficiency. Shi et al. (2010) [45] show that, during 2000-2006, the industry sector of eastern region has the best energy efficiency. Similar conclusions are made by Wang et al. (2013) [46], Yao et al. (2015) [47], and Lin and Zhao (2016) [48]. While the main conclusion is that the energy efficiency decreases from southeast to northwest, we still have other important findings from considering the city point of view. The main conclusions of this study are as follows:

First, by using space econometrics technology, we find multi-stage DEA model ignores space spillover effect between two adjacent units. It is a biased evaluation method. Compared with city, using province as evaluation unit will result in overestimation and bias.

Second, from 2001 to 2012, Chinese TFEE remain low all the time, which is between 0.54 and 0.66 and mean is 0.57 , the energy-saving potential is up to $34-46 \%$ and its development tendency displays an inverted " $U$ " type. The TFEE of Chinese eastern region, central region, western region and northeastern region are respective $0.61,0.51,0.59$ and 0.54 . The internal difference of TFEE of central region is lowest, followed by western region, eastern region and northeastern region, which is the largest. The dynamic tendency of TFEE of four regions shows the same characteristic as the nation's. The total number of cities whose efficiency is in the frontier are between 27 and 37, most of them are province capitals and economically developed cities located in Yangtze River Delta region and Pearl River Delta region. The Bottom 10 cities whose TFEE are lowest are mainly located in the central and western regions, which are resource-based cities. The TFEE of Chinese cities are spatial cluster and cities that have higher spatial cluster of population and economy activity also have higher TFEE.

Third, spatial agglomeration, industry structure, technology level, infrastructure and energy endowment are five environment factors that can have a significant effect on the TFEE. Therefore, adjusting input factors to assess energy efficiency can truly reflect the energy management level of disadvantaged environment regions. For enhancing TFEE, cities that located in disadvantaged environment regions should improve the spatial agglomeration of economy activities, reduce the proportion of secondary industry, attract foreign direct investment and improve the quality of basic infrastructure.

Fourth, from 2001 to 2012, Chinese TFEME is significant higher than TFEE; it is up to 27.04\%, and, overall, displays a fluctuated upward tendency. The TFEEE is all less than 1 and display a fluctuated downward tendency. Management inefficiency and environment inefficiency are the main reasons that Chinese TFEE is low. However, if the influence of external inferior environmentis not removed, we will underestimate Chinese TFEME. The change of Chinese TFEE is mainly affected by TFEEE. Improving exogenous environment is an important direction for China to improve TFEE.

According to Yao, et al. (2012) [49], we have six policies to control the surging energy consumption and to ensure sustainable economic growth. The first policy measure is for China to accelerate the pace of its economic structure transformation. Instead of focusing on a single target of achieving certain levels of aggregated GDP growth, more attention should be paid to value-added and job creation in different industries. The second policy measure is for China to change its export structure, which has been dominated by low-quality cheap energy-intensive products, and has accounted for at least 
one-third of the energy consumed by China. The third policy measure is to reform the pricing system. To protect the households and, to a lesser extent, industrial and commercial enterprises, China sets strict restrictions on the consumer prices of primary energy products, such as coal and crude oil. This means that energy prices in China do not fully reflect environmental impacts, resources scarcity, and supply and demand imbalances. Such low energy prices foster the growth of energy intensive industries, reduce pressure to improve energy efficiency, and encourage wasteful consumption. The fourth policy measure to help curb energy consumption is to increase public awareness and enforce tougher standards on building design. The fifth policy measure is to ensure energy security. The government should provide more financial support for domestic energy exploration and production, and for mass transit construction. The sixth policy is to diversify the country's energy sources. Because it is hard to transform China's coal-based energy consumption structure, another way to improve its energy efficiency is to adjust its energy structure via technological change and management advancement.

Currently, research into the energy efficiency of Chinese city is still at an early stage as a large number of researchers choose province as their research object. This paper only conducts the research from the perspectives of descriptive statistics by using three-stage SBM model and does not consider other methods to estimate the energy efficiency of Chinese cities to compare different results. In addition, we only use the desirable output without using undesirable output. In the future, a more precise measurement of DEA model with both desirable and undesirable outputs could be implemented and compared with using a complicated approach, such as the super DEA model that measures the rank of efficient DMUs, and the window analysis that evaluates the dynamic effect of efficiency change. We could also try to use the econometric approach with fixed effects model to analyze the factors influencing energy efficiency.

Author Contributions: All authors contributed equally to this work, especially Haifeng Huang collected the data and conceived the whole project, Tao Wang contributed econometrics analysis and writing.

Conflicts of Interest: The authors declare no conflict of interest.

\section{References}

1. Lu, B.; Wang, K.; Xu, Z. China's Regional Energy Efficiency: Results based on three-stage DEA model. Int. J. Glob. Energy Issues 2015, 5, 652-667. [CrossRef]

2. World Bank. China: Improving Energy Efficiency in Public Institutions; Energy Sector Management Assistance Program (ESMAP) Report; World Bank: Washington, DC, USA, 2015.

3. Tonini, A. The EEC Commission and European Energy Policy: A Historical Appraisal; Springer: Cham, Switzerland, 2016.

4. Bosseboeuf, D.; Chateau, B.; Lapillonne, B. Monitoring Energy Efficiency and $\mathrm{CO}_{2}$ Abatement Policies: What can we learn from indicators. In Proceedings of the Workshop on Best Practices in Policies and Measures, Copenhagen, Denmark, 11-13 April 2000.

5. Barcelona, E. Sectoral Energy Indicators. In Presentation on the Joint EGEDA and EGEEC Workshops on APEC Energy Database and Energy Efficiency Indicators; National University of Singapore: Singapore, 2007.

6. Hu, J.; Wang, S. TFEE of Regions in China. Energy Policy 2006, 7, 3206-3217. [CrossRef]

7. Honma, S.; Hu, J.L. Total-Factor Productivity Growth of Regions in Japan. Energy Policy 2009, 37, 3941-3950. [CrossRef]

8. Hu, J.L.; Kao, C.H. Efficient Energy Saving Targets for APEC Economies. Energy Policy 2007, 35, 373-382. [CrossRef]

9. Zhou, P.; Poh, K.L.; Ang, B.W. A Non-Radial DEA Approach to Measuring Environmental Performance. Eur. J. Oper. Res. 2007, 178, 1-9. [CrossRef]

10. Zhou, P.; Ang, B.W.; Poh, K.L. Measuring Environmental Performance under Different Environmental DEA Technologies. Energy Econ. 2008, 30, 1-14. [CrossRef]

11. Bian, Y.W.; Yang, F. Resource and Environment Efficiency Analysis of Provinces in China: A DEA approach based on Shannon's entropy. Energy Policy 2010, 38, 1909-1917. [CrossRef] 
12. Li, L.B.; Hu, J.L. Ecological total-factor energy efficiency of regions in China. Energy Policy 2012, 46, $216-224$. [CrossRef]

13. Sun, J.W.; Xiao, C.M. The Change of Total Factor Energy Efficiency in the Yangtze River Delta Region. China Popul. Resour. Environ. 2012, 12, 67-72.

14. Qin, B.T. Chinese Regional Energy Efficiency-Perspective of City. World Econ. Pap. 2014, 1, 95-104.

15. Lin, B.; Du, K. Energy and $\mathrm{CO}_{2}$ Emissions Performance in China's Regional Economies: Do market-oriented reforms matter? Energy Policy 2015, 78, 113-124. [CrossRef]

16. Fukuyama, H.; Weber, W. A Directional Slacks-based Measure of Technical Inefficiency. Socio-Econ. Plan. Sci. 2009, 4, 469-492. [CrossRef]

17. Bian, Y.; Hu, M.; Wang, Y.; Xu, H. Energy Efficiency Analysis of the Economic System in China during 1986-2012: A parallel slacks-based measure approach. Renew. Sustain. Energy Rev. 2016, 55, 990-998. [CrossRef]

18. Zhou, Y.; Xing, X.; Fang, K.; Liang, D.; Xu, C. Environmental Efficiency Analysis of Power Industry in China Based on an Entropy SBM Model. Energy Policy 2013, 57, 68-75. [CrossRef]

19. Zhang, N.; Choi, Y. Environmental Energy Efficiency of China's Regional Economies: A non-oriented slacks-based measure analysis. Soc. Sci. J. 2013, 50, 225-234. [CrossRef]

20. Timmer, C. Using a Probabilistic Frontier Production Function to Measure Technical Efficiency Efficiency. J. Political Econ. 1997, 4, 776-794. [CrossRef]

21. Pan, X.F. The Dynamic Evolution of Spatial Pattern of Chinese Regional Differences in Energy Efficiency. Manag. Rev. 2012, 11, 13-19.

22. Lesage, J.; Pace, R. Introduction to Spatial Econometrics; CRC Press: New York, NY, USA, 2010.

23. Mardani, A.; Zavadskas, E.K.; Streimikiene, D.; Jusoh, A.; Khoshnoudi, M. A Comprehensive Review of Data Envelopment Analysis Approach in Energy Efficiency. Renew. Sustain. Energy Rev. 2016, 3, 1178-1198. [CrossRef]

24. Zhang, X.; Cheng, X.; Yuan, J. TFEE in Developing Countries. Energy Policy 2011, 2, 644-650. [CrossRef]

25. Horta, I.M.; Camanho, A.S.; DaCosta, J.M. Performance Assessment of Construction Companies Integrating Key Performance Indicators and Data Envelopment Analysis. J. Constr. Eng. Manag. 2009, 136, 581-594. [CrossRef]

26. Goldemberg, J.; Prado, L.T.S. The Decline of the World's Energy Intensity. Energy Policy 2011, 39, $1802-1805$. [CrossRef]

27. Glaeser, E.; Kahn, M. The Greenness of Cities: Carbon Dioxide Emissions and Urban Development. J. Urban Econ. 2010, 3, 404-418. [CrossRef]

28. Hallegatte, S.; Henriet, F.; Corfee, M. The Economics of Climate Change Impacts and Policy Benefits at City Scale: A Conceptual Framework. Clim. Chang. 2011, 104, 52-87. [CrossRef]

29. Chen, Y.; Liu, B.; Shen, Y.; Wang, X. The Energy Efficiency of China's Regional Construction Industry Based on the Three Stage DEA Model and the DEA-DA Model. KSCE J. Civ. Eng. 2016, 20, 34. [CrossRef]

30. Nezinsky, E. Eco-Efficiency and Human Capital in Europe: Quantitative Assessment. In Proceedings of the Management, Knowledge and Learning Joint International Conference 2015, Bari, Italy, 27-29 May 2015.

31. Fukuyama, H.; Weber, W.L. A Slacks-Based Inefficiency Measure for a Two-Stage System with Bad Outputs. Omega 2010, 5, 398-409. [CrossRef]

32. Tone, K. A Slacks-Based Measure of Efficiency in Data Envelopment Analysis. Eur. J. Oper. Res. 2001, 3, 498-509. [CrossRef]

33. Tone, K.; Tsutsui, M. Network DEA: A Slacks-based Measure Approach. Eur. J. Oper. Res. 2009, 197, $243-252$. [CrossRef]

34. Ashrafi, A.; Jaafar, A.B.; Lee, L.S.; Abu Bakar, M.R. A Slacks-Based Measure of Efficiency in Two-Stage Data Envelopment Analysis. Int. J. Math. Anal. 2011, 5, 1435-1444.

35. Banker, R.D.; Charnes, A.; Cooper, W.W. Some Models for Estimating Technical and Scale Inefficiencies in Data Envelopment Analysis. Manag. Sci. 1984, 30, 1078-1092. [CrossRef]

36. Coelli, T.; Rao, D.; Donnell, C. An Introduction to Efficiency and Productivity Analysis; Springer: New York, NY, USA, 2005.

37. Rasche, R.H.; Tatom, J.A. Energy Resources and Potential GNP; Federal Reserve Bank of St. Louis: St. Louis, MO, USA, 1977; pp. 10-24. 
38. Liu, B.S.; Chen, X.H.; Wang, X.Q.; Chen, Y. Development Potential of Chinese Construction Industry in the New Century Based on Regional Difference and Spatial Convergence Analysis. KSCE J. Civ. Eng. 2014, 18, 11-18. [CrossRef]

39. Liu, B.S.; Wang, X.Q.; Chen, C.L.; Ma, Z.J. Research into the Dynamic Development Trend of the Competitiveness of China's Regional Construction Industry. KSCE J. Civ. Eng. 2014, 18, 1-10. [CrossRef]

40. Hall, R.; Jones, C. Why do Some Countries Produce so Much More Output Per Worker than Others. Q. J. Econ. 1999, 114, 83-116. [CrossRef]

41. Cohen, W.; Lebinthal, D. Innovation and Learning: The two faces of R\&D. Econ. J. 1989, 397, 569-596.

42. National Bureau of Statistics of China. China Statistics Yearbook 2001-2012; China Statistic Press: Beijing, China, 2013.

43. National Bureau of Statistics of China. Chinese Town and City Statistics Yearbook 2001-2012; China Statistic Press: Beijing, China, 2013.

44. National Bureau of Statistics of China. Chinese Regional Economic Statistics Yearbook 2001-2012; China Statistic Press: Beijing, China, 2013.

45. Shi, G.M.; Bi, J.; Wang, J.N. Chinese Regional Industrial Energy Efficiency Evaluation Based on A DEA model of Fixing Non-Energy Inputs. Energy Policy 2010, 10, 6172-6179. [CrossRef]

46. Wang, Q.W.; Zhao, Z.Y.; Zhou, P.; Zhou, D.Q. Energy Efficiency and Production Technology Heterogeneity in China: A Meta-frontier DEA Approach. Econ. Model. 2013, 35, 283-289. [CrossRef]

47. Yao, X.; Zhou, H.C.; Zhang, A.Z.; Li, A.J. Regional Energy Efficiency, Carbon Emission Performance and Technology Gaps in China: A Meta-frontier Non-radial Directional Distance Function Analysis. Energy Policy 2015, 84, 142-154. [CrossRef]

48. Lin, B.Q.; Zhao, H.L. Technology Gap and Regional Energy Efficiency in China's Textile Industry: A Non-parametric Meta-frontier Approach. J. Clean. Prod. 2016, 137, 21-28. [CrossRef]

49. Yao, S.J.; Luo, D.; Rooker, T. Energy Efficiency and Economic Development in China. Asian Econ. Pap. 2012, 2, 99-117. [CrossRef]

(C) 2017 by the authors. Licensee MDPI, Basel, Switzerland. This article is an open access article distributed under the terms and conditions of the Creative Commons Attribution (CC BY) license (http:/ / creativecommons.org/licenses/by/4.0/). 